\title{
OPN Polymorphism is Associated with the Susceptibility to Cervical Spondylotic Myelopathy and its Outcome After Anterior Cervical Corpectomy and Fusion
}

\author{
Jibin Wu Dongying Wu Kaijin Guo Feng Yuan Bo Ran \\ Department of Orthopaedics, The Affiliated Hospital of Xuzhou Medical College, Xuzhou China
}

\section{Key Words}

Cervical spondylotic myelopathy - Osteopontin - Susceptibility • Cervical corpectomy and fusion

\begin{abstract}
Background: Osteopontin (OPN) is reportedly involved in bone desorption, formation and ectopic calcification. We sought to investigate the role of OPN gene polymorphism in the susceptibility to Cervical spondylotic myelopathy (CSM) and in predicting the outcome anterior cervical corpectomy and fusion (ACF). Methods: A total of 187 patients diagnosed with CSM and 233 sex and age matched healthy controls were enrolled in this study. All CSM patients received ACF and were followed up for 24 months. The polymorphisms of OPN gene at 3 loci, namely, -156 G>GG, -443 C > T and -66T>G were determined. Results: The -66T > G genotype was significantly different between CSM patients and controls. Compared to the -66TT carriers, the -66GG genotype carriers had a higher risk for developing CSM (adjusted Odd Ratio=2.58, adjusted $P=0.001$ ). In contrast, the genotype distributions of the $-156 \mathrm{G} / \mathrm{GG}$ and $-443 \mathrm{C} / \mathrm{T}$ loci were not significantly different between the CSM and control groups. OPN gene polymorphism did not determine the pre-operative severity of CSM patients, but the $-66 T>G$ genotype was significantly associated with the clinical outcome of CSM after ACF treatment. The $-66 \mathrm{~T}>\mathrm{G}$ did not affect the serum OPN level, but affect the local expressions of OPN and a serious of key inflammatory factors in the intervertebral disc samples. Conclusion: Our study shows the OPN -66T>G genetic polymorphism contributes to patients' susceptibility to CSM and could be indicative of the outcome of ACF surgery.
\end{abstract}

Copyright $\odot 2014$ S. Karger AG, Basel 
Wu et al.: OPN Polymorphism and Cervical Spondylotic Myelopathy

\section{Introduction}

Cervical spondylotic myelopathy (CSM) is a well-known clinical syndrome in the elderly. CSM is described by the symptoms and signs caused by stimulation and compression of the spinal cord due to cervical intervertebral disk degeneration diseases and secondary changes. Epidemiological studies show that environmental factors, including age, gender, smoking and obesity were responsible for the incidence of chronic spine disorders [1,2]. Additionally, the genetic factor is also involved in the degeneration process of spine disorders, including $\operatorname{CSM}[3,4]$.

Osteopontin (OPN) is an acidic, noncollagenous matrix protein produced by the bone and kidneys. OPN is associated with many pathologic conditions, including cancer [5], autoimmune disease [6], and cardiovascular disease [7,8]. Moreover, OPN is reportedly involved in bone desorption and formation [9]. Recent study shows that high serum OPN level is associated with a low bone mineral density in postmenopausal women [10]. OPN also well known as a molecule that consistently colocalizes with ectopic calcification and is over-expressed in the hyperostotic spinal lesions [11].

The expression of OPN is significantly influenced by its genetic polymorphisms of the promoter [12]. Several polymorphisms in the human OPN encoding gene have been identified in different populations, of which the $-156 \mathrm{G}>\mathrm{GG},-443 \mathrm{C}>\mathrm{T}$ and $-66 \mathrm{~T}>\mathrm{G}$ polymorphisms are mostly studied. These OPN genetic polymorphisms have been reported in association with inflammatory disease e.g. systemic lupus erythematosus [13], chronic hepatitis C [14], lupus nephritis [15] and large artery atherosclerosis [16]. However the role of OPN expression and its gene polymorphisms with CSM remains unknown.

\section{Materials and Methods}

\section{Enrolment}

A total of 187 patients diagnosed with CSM were enrolled in the study from September 2007 to June 2011. The diagnoses were established on the basis of findings from the history, physical examination and confirmed by magnetic resonance imaging [17] as previously described. The control samples consisted of 233 sex and age matched healthy Chinese individuals with negative MRI findings. Exclusion criteria included congenital cervical anomalies, trauma, prior cervical surgery, rheumatoid arthritis, infections, tumors, ankylosing spondylitis, ossification of the posterior longitudinal ligament, diffuse idiopathic skeletal hyperostosis, and any other inflammatory disease involving the cervical spine. The clinical characteristics including sex, age, weight, height, body mass index (BMI), daily desk work time, smoking status and family history of intervertebral degenerative disc disease were collected. The study protocol was approved by the Ethics Committees Ethical Committee at Department of orthopedics, The Affiliated Hospital of Xuzhou Medical College, Written informed consent was obtained from all patients before participation in the study.

\section{Follow-Up and Outcome Assessment}

All patients received anterior cervical corpectomy and fusion (ACF) and were followed up. Based on the clinical symptoms and signs, the severity of neurological deficits of all these preoperative patients was scored one day before and 24 months after ACF according to the modified Japanese Orthopedic Association (modified JOA) score for CSM. [18] The patients were dichotomized into two groups according to the mJOA scores: improvement group (at least $50 \%$ or higher improvement in mJOA score at the last follow-up compared with the pre-operative score) and a non-improvement group (the improvement of mJOA score at last follow-up was less than 50\%, equal, or less than the pre-operative mJOA score) [19].

\section{Measurement of serum OPN}

Serum OPN levels were measured using the Quantikine Human OPN immunoassay kit (R\&D Systems, Minneapolis, MN, USA) according to the manufacturer's instructions. Intraassay coefficient of variation (CV) was $4 \%$ and inter-assay CV was $6.6 \%$. 
Western blot assay

The intervertebral disc samples were collected during surgery from CSM patients underwent the anterior cervical corpectomy and fusion. Samples were homogenized and lysed. Extracts were resolved on SDS-polyacrylamide gels followed by transferring to nitrocellulose membranes (BioRad). Proteins were detected by using antibodies against OPN (1:1000, Abcam, USA), interleukin-12 (IL12, Abcam, USA), tumor necrosis factor alpha (TNF- $\alpha$, Abcam, USA) and interferon- $\gamma$ (IFN- $\gamma$ ) and GAPDH (1:5000, Santa Cruz). The intensity of the specific bands was calculated using densitometry analysis (Image Station 4000R Pro; Eastman Kodak, Rochester, NY). The quantitative analyses were performed by using TINA software. The OPN expression levels were quantified by the ratio between the individual density of OPN band minus background and GAPDH minus background.

\section{OPN gene polymorphisms}

DNA was extracted from peripheral whole blood using a Qiagen DNA Isolation Kit (Qiagen, Valencia, CA, USA). Three single nucleotide polymorphisms in the promoter region of $O P N$ gene, including $-66 \mathrm{~T}>\mathrm{G}$ (rs28357094), -156G>/GG (rs17524488), and -443C>T (rs11730582), were determined using the TaqMan 5' allelic discrimination assay. It was performed using a commercially available kit Assays-on-DemandTM SNP genotyping products (Applied Biosystems, Foster City, CA). SNP amplification assays were used according to the manufacturer's instructions. In short, $10 \mathrm{ng}$ of sample DNA in $25 \mu \mathrm{L}$ of reaction solution containing 12.5 $\mu \mathrm{L}$ of the $2 \times$ TaqMan $®$ Universal PCR Mix (Applied Biosystems), and $1.25 \mu \mathrm{l}$ of pre-developed assay reagent from the SNP genotyping product containing two primers and two MCB-Taqman probes. Reaction condition was consisted of pre incubation at $50^{\circ} \mathrm{C}$ for $2 \mathrm{~min}$, at $95^{\circ} \mathrm{C}$ for $10 \mathrm{~min}$, followed by 40 cycles of $95^{\circ} \mathrm{C}$ for 15 $\mathrm{s}$ and $60^{\circ} \mathrm{C}$ for $1 \mathrm{~min}$. Amplifications were performed in an ABI Prism ${ }^{\circ} 7500$ Sequence Detection System (Applied Biosystems).

\section{Statistical Analysis}

Data on quantitative characteristics are expressed as means \pm SD. Data on qualitative characteristics are expressed as percent values or absolute numbers, as indicated. Differences in demographic characteristics and vascular risk factors between patients and controls were compared by using Student's test or ANOVA for continuous variables and the $\chi 2$ test for all categorical variables. To estimate the deviation of frequency of gene alleles in the tested population, we performed the Hardy-Weinberg equilibrium using $\chi 2$ tests. Genotypes and allele frequencies were compared by the $\chi 2$ analysis or Fisher's exact test. Multivariate logistic regression analysis was used to determine the influence of OPN polymorphisms on CSM, controlling potential confounding conventional risk factors. A forward stepwise (Likelihood Ratio) procedure was used for the multivariable analysis. Data were analyzed using the SPSS 16.0 package (Statistical Package for the Social Sciences, version 16.0, SPSS Inc, Chicago, IL, USA).The results were considered statistically significant at $\mathrm{P}<0.01$ using a 2 -tailed test.

\section{Results}

Table 1 shows the clinical characteristics of CSM patients and controls. There was no significant difference in age, sex and BMI between two groups; however, CSM patients had significantly higher rates of smokers and family history and longer daily desk work working time than controls (all $\mathrm{P}<0.05$ ).

Table 2 describes the genotype and allele distributions of OPN gene polymorphisms in the CSM and control groups. The genotype frequencies for all polymorphisms did not differ significantly from those expected under Hardy-Weinberg equilibrium (all P>0.05). For the $-66 \mathrm{~T}>\mathrm{G}$ polymorphism, CSM patients had a higher prevalence of GG genotype than the controls (27.42\% vs.16.31\%, $\mathrm{P}<0.001)$. We performed the univariate and multivariate logistic regression analysis with the adjustment of age, sex, BMI, smoking status, family history status and daily desk work time. Compared with the -66TT carriers, our data showed that the $-66 \mathrm{GG}$ genotype carriers were significantly related to a higher CSM risk (adjust $0 \mathrm{R}=2.58$, 95\%CI: 1.44-4.59, adjusted $\mathrm{P}=0.001$ ). In contrast, the genotype distribution of $-156 \mathrm{G} / \mathrm{GG}$ and $-443 \mathrm{C} / \mathrm{T}$ were not significantly different between the CSM and control groups. 
Table 1. Characteristics of subjects in the CSM and control groups

\begin{tabular}{llll}
\hline Variables & Case & Control & $\mathrm{P}$ \\
\hline & & & \\
Age(mean \pm SD) & $46.2 \pm 3.8$ & $45.9 \pm 2.5$ & 0.476 \\
Gender (Male, \%) & 62.4 & 61.7 & 0.812 \\
BMI(mean \pm SD) & $22.8 \pm 1.4$ & $23.1 \pm 1.5$ & 0.652 \\
Smoker (\%) & 33.7 & 23.1 & $<0.001$ \\
Family history (\%) & 22.1 & 7.8 & $<0.001$ \\
Daily desk work time & $5.1 \pm 1.2$ & $4.6 \pm 2.3$ & $<0.001$ \\
\hline
\end{tabular}

Table 2. The genotypic and allelic frequencies of OPN gene polymorphisms between the CSM and control subjects

\begin{tabular}{|c|c|c|c|c|c|c|c|c|c|}
\hline & & CSM & $\%$ & Control & $\%$ & $\begin{array}{c}\text { adjusted } \\
\text { OR }\end{array}$ & \multicolumn{2}{|c|}{$95 \% \mathrm{Cl}$} & $\begin{array}{c}\text { adjusted } \\
\text { P }\end{array}$ \\
\hline \multirow[t]{5}{*}{$-66 \mathrm{~T}>\mathrm{G}$} & TT & 37 & $19.79 \%$ & 71 & $30.47 \%$ & 1.00 & & & \\
\hline & TG & 99 & $52.94 \%$ & 124 & $53.22 \%$ & 1.53 & 0.95 & 2.47 & 0.079 \\
\hline & GG & 51 & $27.27 \%$ & 38 & $16.31 \%$ & 2.58 & 1.44 & 4.59 & 0.001 \\
\hline & $\mathrm{T}$ & 173 & $46.26 \%$ & 266 & $57.08 \%$ & 1.00 & & & \\
\hline & G & 201 & $53.74 \%$ & 200 & $42.92 \%$ & 1.55 & 1.18 & 2.03 & 0.002 \\
\hline \multirow[t]{5}{*}{$-156 \mathrm{G} / \mathrm{GG}$} & GG & 69 & $36.90 \%$ & 92 & $39.48 \%$ & 1.00 & & & \\
\hline & GGG & 85 & $45.45 \%$ & 101 & $43.35 \%$ & 1.12 & 0.73 & 1.72 & 0.595 \\
\hline & GGGG & 33 & $17.65 \%$ & 40 & $17.17 \%$ & 1.10 & 0.63 & 1.92 & 0.737 \\
\hline & $\mathrm{G}$ & 223 & $59.63 \%$ & 285 & $61.16 \%$ & 1.00 & & & \\
\hline & GG & 151 & $40.37 \%$ & 181 & $38.84 \%$ & 1.07 & 0.81 & 1.41 & 0.651 \\
\hline \multirow[t]{5}{*}{$-443 \mathrm{C} / \mathrm{T}$} & $\mathrm{CC}$ & 57 & $30.48 \%$ & 60 & $25.75 \%$ & 1.00 & & & \\
\hline & CT & 93 & $49.73 \%$ & 129 & $55.36 \%$ & 0.76 & 0.48 & 1.19 & 0.229 \\
\hline & TT & 37 & $19.79 \%$ & 44 & $18.88 \%$ & 0.89 & 0.50 & 1.56 & 0.674 \\
\hline & $\mathrm{C}$ & 207 & $55.35 \%$ & 249 & $53.43 \%$ & 1.00 & & & \\
\hline & $\mathrm{T}$ & 167 & $44.65 \%$ & 217 & $46.57 \%$ & 0.93 & 0.70 & 1.22 & 0.580 \\
\hline
\end{tabular}

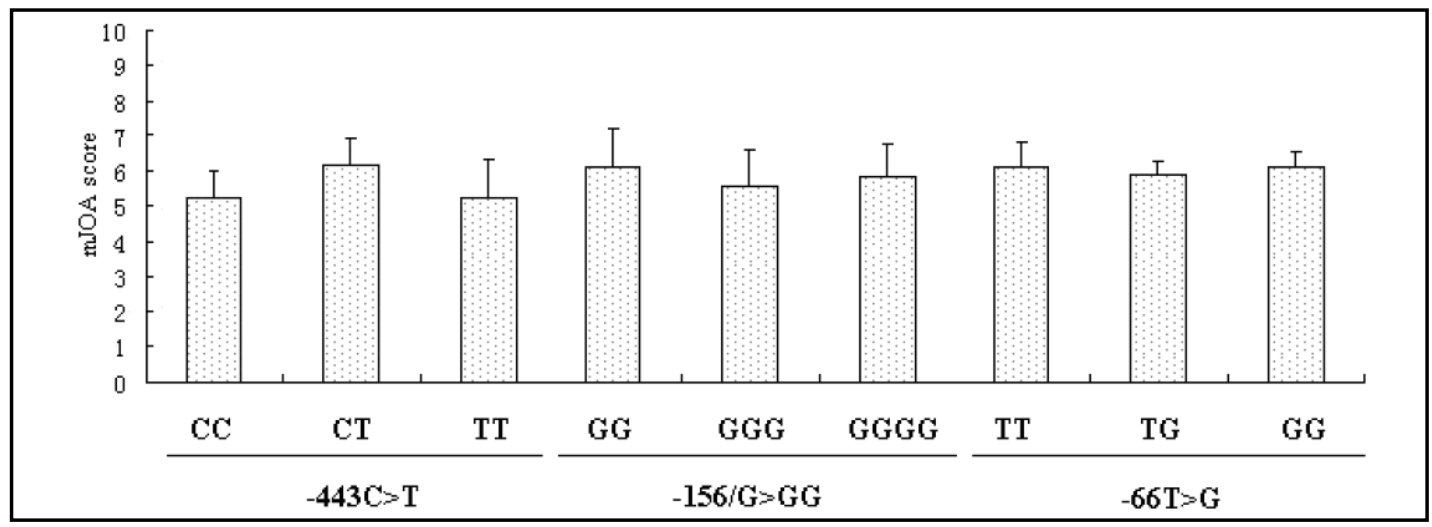

Fig. 1. The CSM severity by mJOA sores among OPN genotype carriers.

We evaluated the relationship of the OPN polymorphism with the severity of CSM patients before CAF treatment using the modified JOA score. We found that the pre-operative severities of patients were similar among different genotype carriers (Fig. 1).

The mean pre-operative and postoperative serum OPN levels were compared according to the OPN genotypes. We found that the OPN levels were not significantly different among different genotype carriers (Fig. 2a and 2b). 
Fig. 2. The mean preoperative and postoperative serum OPN levels according to the OPN genotypes.

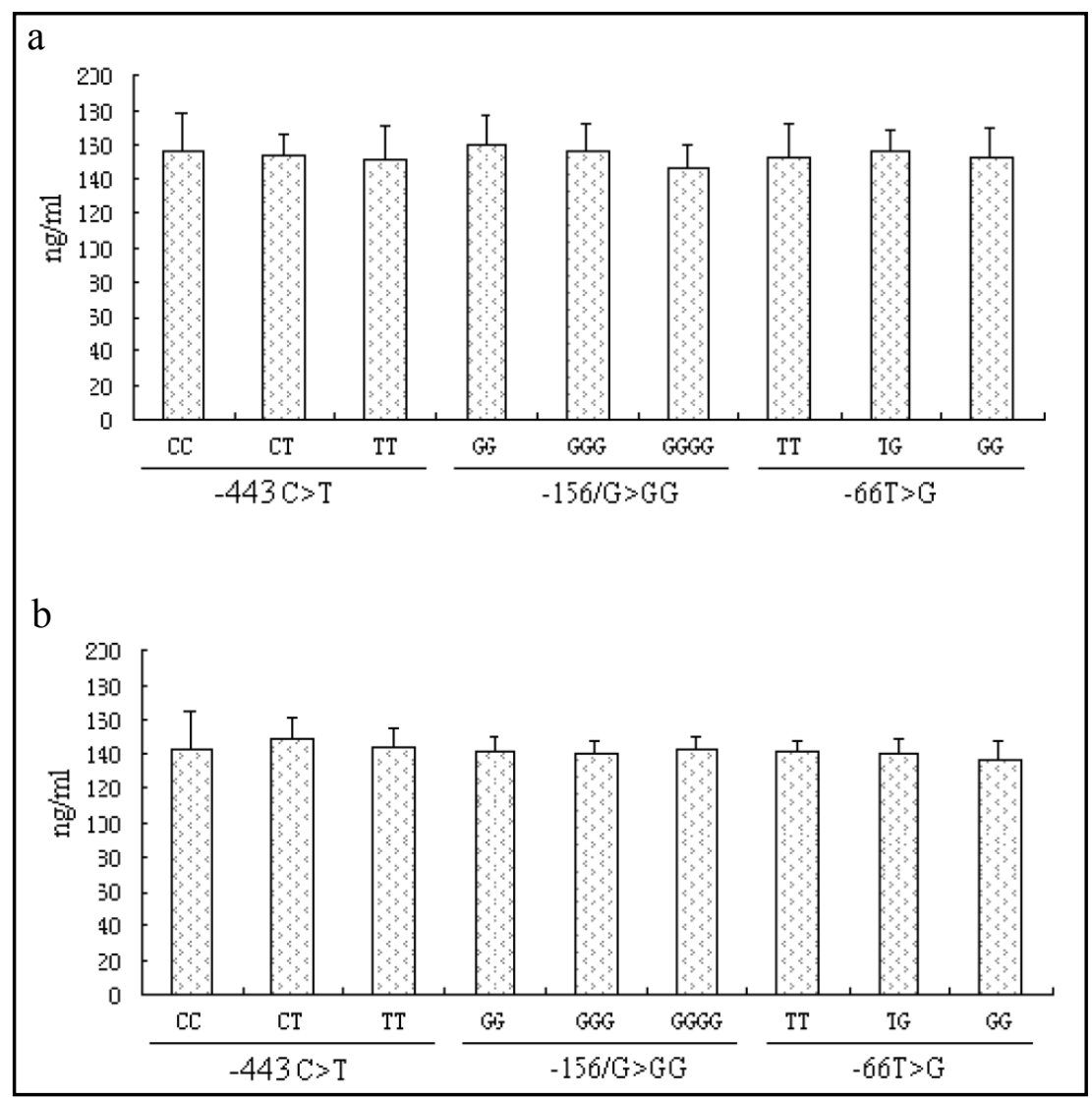

Fig. 3. The expression of OPN and several key inflammatory factors in intervertebral disc samples from three different CSM patients according to $-66 \mathrm{~T}>\mathrm{G}$ genotype.

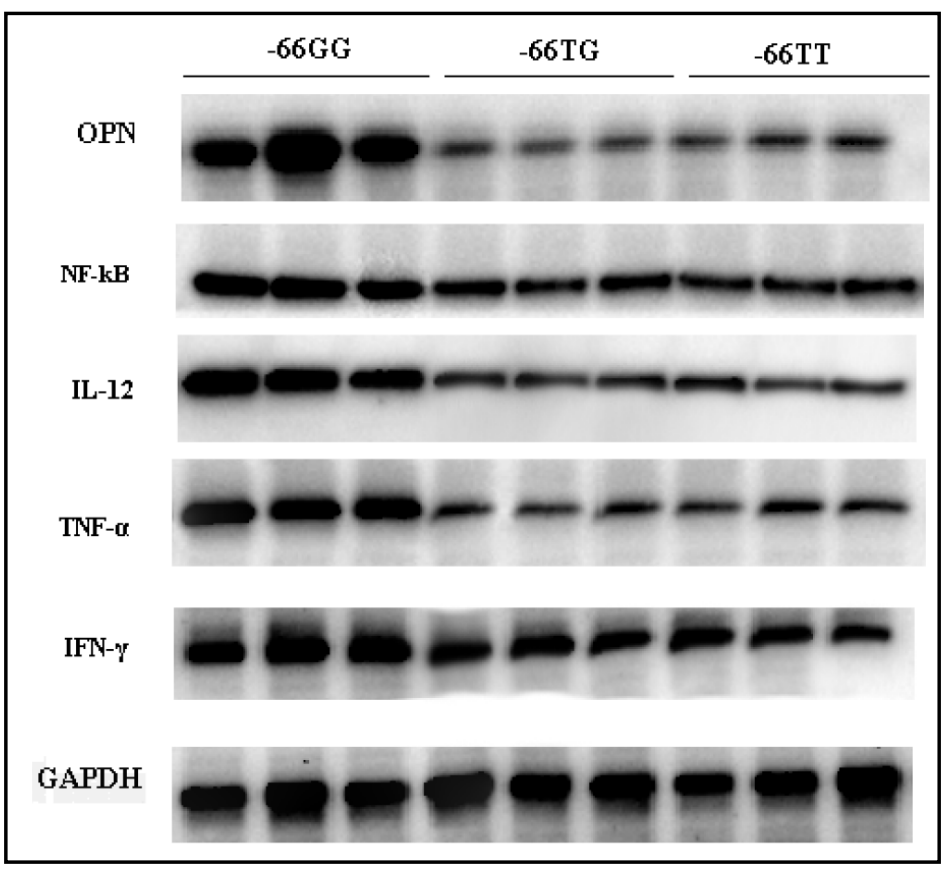

We next compared the OPN expression in intervertebral disc samples from CSM patients underwent CAF treatment. Figure 3 shows the typical bands of samples from CSM patients. Our results showed that the $-66 \mathrm{~T}>\mathrm{G}$ gene polymorphisms significantly affected the local OPN expression in intervertebral disc. The OPN expression was apparently lower in the -66TT 
Wu et al.: OPN Polymorphism and Cervical Spondylotic Myelopathy

Table 3. The association between $-66 \mathrm{~T}>\mathrm{G}$ polymorphism and the CSM outcome after ACF treatment

\begin{tabular}{ccccccccccc}
\hline & \multicolumn{1}{c}{ ACF without improvement } & \multicolumn{2}{c}{ ACF with Improvement } & $\begin{array}{c}\text { adjusted } \\
\text { OR }\end{array}$ & 95\%CI & $\begin{array}{c}\text { adjusted } \\
\text { P }\end{array}$ \\
\hline$-66 \mathrm{~T}>\mathrm{G}$ & TT & 15 & $17.65 \%$ & 23 & $22.55 \%$ & 1.00 & & & \\
& TG & 44 & $51.76 \%$ & 68 & $66.67 \%$ & 0.99 & 0.47 & 2.11 & 0.984 \\
& GG & 26 & $30.59 \%$ & 11 & $10.78 \%$ & 3.62 & 1.39 & 9.46 & 0.007 \\
& T & 74 & $43.53 \%$ & 114 & $55.88 \%$ & 1.00 & & & \\
G & 96 & $56.47 \%$ & 90 & $44.12 \%$ & 1.64 & 1.09 & 2.48 & 0.017 \\
\hline
\end{tabular}

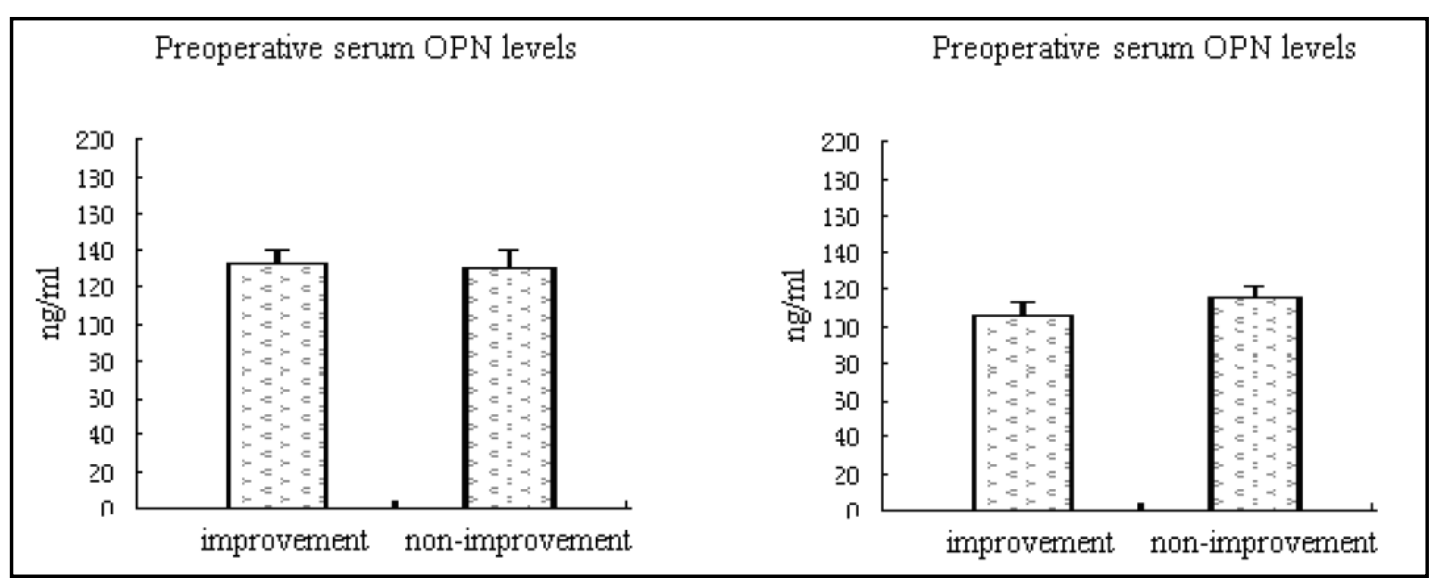

Fig. 4. The preoperative and postoperative serum OPN levels between patients with improvement and those without improvement.

carriers compared to the -66CC and -66CT carriers. Interestingly, we noted that the -66GG carriers also had significantly higher expressions of a serious of key inflammatory factors, including IL-12, TNF- $\alpha$ and IFN- $\gamma$ (Fig. 3). In contrast, the $-443 \mathrm{C}>\mathrm{T}$ and $-156 \mathrm{G}>\mathrm{GG}$ did not affect the OPN protein expression and the above mentioned inflammatory factors (data not shown).

All 187 patients receiving ACF in this study completed the 24 months follow-up study. No patients died or lost contact during the follow-up periods. According to the modified JOA scores, 102 patients were attributed into improvement group and 85 into non-improvement groups. We observed a significant difference in the $-66 \mathrm{~T}>\mathrm{G}$ polymorphisms between improvement and non-improvement groups. The improvement group had a significantly higher rate of TT genotype distribution than those without improvement $30.59 \%$ vs. $10.78 \% \mathrm{P}=0.002, \mathrm{P}<0.001$ ). After adjustment with sex, age, BMI, smoke status, desk work time, family history and surgical treatment, logistic regression analysis showed that the TT of $-66 \mathrm{~T}>\mathrm{G}$ polymorphisms is associated with a higher chance of gaining improvement from ACF surgery (adjusted OR=3.62, adjusted $\mathrm{P}=0.007$, compared to CC genotype, Table 3 ). The genotype and allele distributions of the other two loci did not show difference between the improvement and non-improvement groups (data not shown).

The preoperative and postoperative serum OPN levels are not significantly different between patients with improvement and those without after ACF treatment (figure 3). Logistic regression analysis showed that the preoperative and postoperative serum OPN levels are not associated with the clinical benefit from ACF surgery in CSM patients.

\section{Discussion}

CSM affects more frequent in patients older than 50 years, due to spinal canal stenosis, anterior compressive osteophytes and spinal hypermobility [20]. Our study showed the 
OPN $-66 \mathrm{~T}>$ G genetic polymorphism contributes to the susceptibility to CSM and could be indicative of the outcome of ACF surgery.

OPN is one of the most abundant non-collagenous proteins in bone [21], originally isolated from bone, and is also found in the kidney, vascular and immune systems [22]. Hou et al reported that Serum OPN is related to LVH incidence in essential hypertension subjects by stimulating cardiomyocyte hypertrophy in vitro, but not OPN gene polymorphisms at $-66 \mathrm{~T} / \mathrm{G},-156 \mathrm{G} / \mathrm{GG}$, and and $-443 \mathrm{C} / \mathrm{T}$ [8]. Serum OPN levels confer the susceptibility and prognosis of ischemic stroke in Chinese patients [23]. In bones, OPN is produced by osteoblasts and osteoclasts, and involved in bone resorption and formation [24]. It has been suggested that OPN may facilitate the adhesion (or detachment) of the osteoclast to the bone surface and act as a signaling molecule or a scaffold in normal bone metabolism and turnover [22, 25, 26]. In human, high OPN levels have been indicated as a risk factor for low bone mineral density in postmenopausal women and used as a biomarker for early osteoporosis diagnosis [27]. Studies have shown that a high level of osteopontin mRNA and protein expression occurs in both intramembranous and endochondral ossification, as well as remodeling bone, including the human osteophyte [28]. The latter has been shown, at least partially, contributing to the pathology of CSM.

In this study, we intended to understand the roles of OPN polymorphisms in CSM, which have previously not been determined. We selected the $-156 \mathrm{G}>\mathrm{GG},-443 \mathrm{~T}>\mathrm{C}$ and $-66 \mathrm{G}>\mathrm{T}$ polymorphisms in the promoter region of the OPN gene that have been mostly studied in other disease conditions. Among the studied polymorphisms, the $-443 \mathrm{~T}>\mathrm{C}$ and $-156 \mathrm{G}>\mathrm{GG}$ polymorphisms have been shown in linkage disequilibrium. The -443 $\mathrm{T}>\mathrm{C}$ polymorphism is at the binding site of MYT1 zinc finger factor and has been formerly correlated to the development of neurogenesis and the status of hepatitis activity [29]. The -156 G>GG polymorphism may interfere with the binding affinity of transcription factor, RUNX2, and has been associated with the increased risk of systemic lupus erythematous [30] and oral squamous cell carcinoma [12, 31, 32]. As for the -66 G>T polymorphism, its implications in disease development have yet been established. Our study indicates that the higher frequency of the -66 GG genotypic carriers among the CSM patients, compared with the paired control. Although the underlying mechanisms are unclear, studies have shown that the expression of OPN is significantly affected by transcription factors and the genetic polymorphisms in the promoter [12]. Thereby, we compared the levels of OPN expression in the intervertebral disc and ligament samples from CSM patients among the -66TT, -66GG and -66GT carriers. Indeed, we found that the OPN expression was greatly lower in the $-66 \mathrm{GG}$ carriers compared with both the $-66 \mathrm{GG}$ and $-66 \mathrm{GT}$ carriers. In contrast, the $-443 \mathrm{C}>\mathrm{T}$ and $-156 \mathrm{G}>\mathrm{GG}$ were not associated with the levels of OPN protein expression. Our results suggest that the $-66 \mathrm{~T}>\mathrm{G}$ gene polymorphisms may affect the protein expression of OPN in intervertebral disc, therefore modifying the carriers' susceptibility to CSM.

Interestingly, we did not see the OPN gene polymorphism affect the serum OPN level, however, we noted the $-66 \mathrm{~T}>\mathrm{G}$ polymorphism influenced the local OPN expression in the intervertebral disc. Also, we found that the-66GG carriers had significantly higher expressions of key cytokines, i.e. NF-kB, IL-12, TNF- $\alpha$, and IFN- $\gamma$ in the intervertebral disc. OPN is an important cytokine that presents at the site of wound and serves as a chemotactic factor to recruit inflammatory cells to the injury site [21]. OPN functions as a pro-inflammatory cytokine and regulates the immune responses by increasing the Th1 cytokines expression, such as IL-12 from macrophages, TNF- $\alpha$ from dendritic cells, and IFN- $\gamma$ and IL-17 by T cells [22]. OPN selectively regulates intercellular adhesion molecule-1(ICAM-1) expression in breast cancer cells via NF-kappa B pathway [33]. The gene polymorphism of OPN was also associated with several inflammatory conditions, such as osteoarthritis [34] and lupus [35]. OPN is expressed in bone matrix. In Chinese patients, the polymorphisms of the OPN $-443 \mathrm{C}>\mathrm{T}$ and the $-66 \mathrm{~T}>\mathrm{G}$ were significantly associated with the osteoarthritis risk and its the radiographic severity by reducing the lower thrombin-cleaved OPN levels in synovial fluid. The OPN rs28357094 (-66T/G in our study) allele was associated with increased serum IFN- $\alpha$ activity in Juvenile Dermatomyositis patients. The OPN allele was most 
strongly enriched in female carriers of TNF-alpha-308A as compared with male carriers of TNF-alpha-308A [36]. Consistent with the above mentioned studies, in the current study, we found that the $-66 \mathrm{~T}>\mathrm{G}$ genotype significantly dramatically affected the expressions of a serious of key inflammatory factors, including NF-kB, IL-12, TNF- $\alpha$ and IFN- $\gamma$.Therefore, the association between OPN genetic polymorphism and development of CSM may be mediated through the increment of cytokine production and the inflammatory process, which might be resulted from injury occurred at the cervical vertebrae.

Our study did not support the correlation between the OPN polymorphism and the severity of CSM using the JOA score. However, the logistic regression analysis indicated that the TT carriers of $-66 T>G$ polymorphisms is associated with a higher chance of gaining improvement from ACF surgery based on the JOA scores. The OPN genetic polymorphism can be used as a disease severity and prognosis marker, e.g., the polymorphism in promoter region of OPN gene reflects the hepatitis activity in chronic hepatitis $\mathrm{C}$ patients [14]. In addition, the OPN gene polymorphism predicts the efficacy of IFN-based therapies in patients with chronic hepatitis C [37]. Our study, for the first time, provide evidence that the OPN -66T $>$ G genotype is correlated to the surgical treatment outcome in CSM patients. Based on the correlation of the $-66 \mathrm{~T}>\mathrm{G}$ genotype and the inflamationatory factor expression, we assume that the different local inflammation level at the cervical spine may be a reason for their different post-operative outcome. Studying the polymorphism of OPN, therefore, may potentially provide an alternative prognostic indicator to evaluate the ACF surgical candidates.

In conclusion, our study suggests that $-66 \mathrm{G}>\mathrm{T}$ polymorphism of the OPN gene may play a pivotal role in the development of CSM via increased production of cytokines and inflammatory activation. It may also be indicative of whether ACF surgical candidates would gain improvement after the surgical treatment. Both a larger scale of investigation on CSM patients and multiple animal studies in vivo or in vitro are necessary to confirm our findings.

\section{References}

1 Oga M, Yuge I, Terada K, Shimizu A, Sugioka Y: Tortuosity of the vertebral artery in patients with cervical spondylotic myelopathy. Risk factor for the vertebral artery injury during anterior cervical decompression. Spine (Phila Pa 1976) 1996;21:1085-1089.

- Emery SE: Cervical spondylotic myelopathy: Diagnosis and treatment. J Am Acad Orthop Surg 2001;9:376388.

- 3 Sakai Y, Matsuyama Y, Hasegawa Y, Yoshihara H, Nakamura H, Katayama Y, Imagama S, Ito Z, Ishiguro N, Hamajima N: Association of gene polymorphisms with intervertebral disc degeneration and vertebral osteophyte formation. Spine (Phila Pa 1976) 2007;32:1279-1286.

- Noponen-Hietala N, Kyllonen E, Mannikko M, Ilkko E, Karppinen J, Ott J, Ala-Kokko L: Sequence variations in the collagen ix and xi genes are associated with degenerative lumbar spinal stenosis. Ann Rheum Dis 2003;62:1208-1214.

5 Johnston NI, Gunasekharan VK, Ravindranath A, O'Connell C, Johnston PG, El-Tanani MK: Osteopontin as a target for cancer therapy. Front Biosci 2008;13:4361-4372.

-6 Chabas D, Baranzini SE, Mitchell D, Bernard CC, Rittling SR, Denhardt DT, Sobel RA, Lock C, Karpuj M, Pedotti R, Heller R, Oksenberg JR, Steinman L: The influence of the proinflammatory cytokine, osteopontin, on autoimmune demyelinating disease. Science 2001;294:1731-1735.

7 Waller AH, Sanchez-Ross M, Kaluski E, Klapholz M: Osteopontin in cardiovascular disease: A potential therapeutic target. Cardiol Rev 2010;18:125-131.

8 Hou X, Hu Z, Huang X, Chen Y, He X, Xu H, Wang N: Serum osteopontin, but not opn gene polymorphism, is associated with lvh in essential hypertensive patients. J Mol Med (Berl) 2014;92:487-495.

-9 Masuda K, Takahashi N, Tsukamoto Y, Honma H, Kohri K: N-glycan structures of an osteopontin from human bone. Biochem Biophys Res Commun 2000;268:814-817.

10 Cho EH, Cho KH, Lee HA, Kim SW: High serum osteopontin levels are associated with low bone mineral density in postmenopausal women. J Korean Med Sci 2013;28:1496-1499. 
Wu et al.: OPN Polymorphism and Cervical Spondylotic Myelopathy

11 Aiba A, Nakajima A, Okawa A, Koda M, Yamazaki M: Evidence of enhanced expression of osteopontin in spinal hyperostosis of the twy mouse. Spine (Phila Pa 1976) 2009;34:1644-1649.

12 Chiu YW, Tu HF, Wang IK, Wu CH, Chang KW, Liu TY, Kao SY: The implication of osteopontin (opn) expression and genetic polymorphisms of opn promoter in oral carcinogenesis. Oral Oncol 2010;46:302306.

13 Trivedi T, Franek BS, Green SL, Kariuki SN, Kumabe M, Mikolaitis RA, Jolly M, Utset TO, Niewold TB: Osteopontin alleles are associated with clinical characteristics in systemic lupus erythematosus. J Biomed Biotechnol 2011;2011:802581.

14 Mochida S, Hashimoto M, Matsui A, Naito M, Inao M, Nagoshi S, Nagano M, Egashira T, Mishiro S, Fujiwara K: Genetic polymorphims in promoter region of osteopontin gene may be a marker reflecting hepatitis activity in chronic hepatitis c patients. Biochem Biophys Res Commun 2004;313:1079-1085.

15 Miyazaki T, Ono M, Qu WM, Zhang MC, Mori S, Nakatsuru S, Nakamura Y, Sawasaki T, Endo Y, Nose M: Implication of allelic polymorphism of osteopontin in the development of lupus nephritis in mrl/lpr mice. Eur J Immunol 2005;35:1510-1520.

16 Kim Y, Lee C: Haplotype analysis revealed a genetic influence of osteopontin on large artery atherosclerosis. J Biomed Sci 2008;15:529-533.

17 Borghaei H, Langer CJ, Millenson M, Ruth KJ, Litwin S, Tuttle H, Seldomridge JS, Rovito M, Mintzer D, Cohen $\mathrm{R}$, Treat J: Phase ii study of paclitaxel, carboplatin, and cetuximab as first line treatment, for patients with advanced non-small cell lung cancer (nsclc): Results of opn-017. J Thorac Oncol 2008;3:1286-1292.

18 Koc RK, Menku A, Akdemir H, Tucer B, Kurtsoy A, Oktem IS: Cervical spondylotic myelopathy and radiculopathy treated by oblique corpectomies without fusion. Neurosurg Rev 2004;27:252-258.

19 Zhang S, Hou X, Zi S, Wang Y, Chen L, Kong B: Polymorphisms of receptor for advanced glycation end products and risk of epithelial ovarian cancer in chinese patients. Cell Physiol Biochem 2013;31:525-531.

20 Chagas H, Domingues F, Aversa A, Vidal Fonseca AL, de Souza JM: Cervical spondylotic myelopathy: 10 years of prospective outcome analysis of anterior decompression and fusion. Surg Neurol 2005;64:S30-S35.

21 Lund SA, Giachelli CM, Scatena M: The role of osteopontin in inflammatory processes. J Cell Commun Signal 2009;3:311-322.

22 Fodor D, Bondor C, Albu A, Simon S-p, Craciun A, Muntean L: The value of osteopontin in the assessment of bone mineral density status in postmenopausal women. J Invest Med 2013;61:15-21.

23 Jing M, Li B, Hou X, Shoba J, Li C, Liang H, Zhang X, Liu E, Yang B, Meng X: Opn gene polymorphism and the serum opn levels confer the susceptibility and prognosis of ischemic stroke in chinese patients. Cell Physiol Biochem 2013;32:1798-1807.

24 Cho E-H, Cho K-H, Lee HA, Kim S-W: High serum osteopontin levels are associated with low bone mineral density in postmenopausal women. J Korean Medical Sci 2013;28:1496-1499.

-25 Shinohara ML, Kim H-J, Kim J-H, Garcia VA, Cantor H: Alternative translation of osteopontin generates intracellular and secreted isoforms that mediate distinct biological activities in dendritic cells. Proc Natl Acad Sci USA 2008;105:7235-7239.

-26 Hou XW, Son J, Wang Y, Ru YX, Lian Q Majiti W, Amazouzi A, Zhou YL, Wang PX, Han ZC: Granulocyte colonystimulating factor reduces cardiomyocyte apoptosis and improves cardiac function in adriamycin-induced cardiomyopathy in rats. Cardiovasc Drugs Ther 2006;20:85-91.

27 Chang I-C, Chiang T-I, Yeh K-T, Lee H, Cheng Y-W: Increased serum osteopontin is a risk factor for osteoporosis in menopausal women. Osteoporosis Int 2010;21:1401-1409.

-28 Dodds RA, Connor JR, James IE, Lee Rykaczewski E, Appelbaum E, Dul E, Gowen M: Human osteoclasts, not osteoblasts, deposit osteopontin onto resorption surfaces: An in vitro and ex vivo study of remodeling bone. J Bone Min Res 1995;10:1666-1680.

29 Mochida S, Hashimoto M, Matsui A, Naito M, Inao M, Nagoshi S, Nagano M, Egashira T, Mishiro S, Fujiwara $\mathrm{K}$ : Genetic polymorphims in promoter region of osteopontin gene may be a marker reflecting hepatitis activity in chronic hepatitis c patients. Biochem Biophys Res Com 2004;313:1079-1085.

-30 Fessler RG, Steck JC, Giovanini MA: Anterior cervical corpectomy for cervical spondylotic myelopathy. Neurosurgery 1998;43:257-265.

31 Hou X, Hu Z, Xu H, Xu J, Zhang S, Zhong Y, He X, Wang N: Advanced glycation endproducts trigger autophagy in cadiomyocyte via rage/pi3k/akt/mtor pathway. Cardiovasc Diabetol 2014;13:78. 
-32 Trivedi T, Franek BS, Green SL, Kariuki SN, Kumabe M, Mikolaitis RA, Jolly M, Utset TO, Niewold TB: Osteopontin alleles are associated with clinical characteristics in systemic lupus erythematosus. BioMed Res Int 2011;2011:802581.

33 Ahmed M, Kundu GC: Osteopontin selectively regulates p70s6k/mtor phosphorylation leading to nfkappab dependent ap-1-mediated icam-1 expression in breast cancer cells. Mol Cancer 2010;9:101.

-34 Balassiano K, Lima S, Jenab M, Overvad K, Tjonneland A, Boutron-Ruault MC, Clavel-Chapelon F, Canzian F, Kaaks R, Boeing H, Meidtner K, Trichopoulou A, Laglou P, Vineis P, Panico S, Palli D, Grioni S, Tumino R, Lund E, Bueno-de-Mesquita HB, Numans ME, Peeters PH, Ramon Quiros J, Sanchez MJ, Navarro C, Ardanaz E, Dorronsoro M, Hallmans G, Stenling R, Ehrnstrom R, Regner S, Allen NE, Travis RC, Khaw KT, Offerhaus GJ, Sala N, Riboli E, Hainaut P, Scoazec JY, Sylla BS, Gonzalez CA, Herceg Z: Aberrant DNA methylation of cancer-associated genes in gastric cancer in the european prospective investigation into cancer and nutrition (epic-eurgast). Cancer Lett 2011;311:85-95.

35 Xu AP, Bai J, Lu J, Liang YY, Li JG, Lai DY, Wan X, Huang HH: Osteopontin gene polymorphism in association with systemic lupus erythematosus in chinese patients. Chin Med J (Engl) 2007;120:2124-2128.

-36 Niewold TB, Kariuki SN, Morgan GA, Shrestha S, Pachman LM: Gene-gene-sex interaction in cytokine gene polymorphisms revealed by serum interferon alpha phenotype in juvenile dermatomyositis. J Pediatr 2010;157:653-657.

37 Naito M, Matsui A, Inao M, Nagoshi S, Nagano M, Ito N, Egashira T, Hashimoto M, Mishiro S, Mochida S, Fujiwara K: Snps in the promoter region of the osteopontin gene as a marker predicting the efficacy of interferon-based therapies in patients with chronic hepatitis c. J Gastroenterol 2005;40:381-388. 